\title{
SOCIO-ECONOMIC STATUS AND GENDER BASED ANALYSIS OF THE EFFECT OF MATHEMATICS ANXIETY ON MATHEMATICS PERFORMANCE AMONG AUSTRALIAN SECONDARY STUDENTS
}

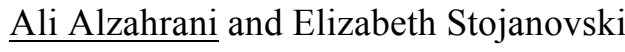 \\ University of Newcastle, Australia \\ alirashashr.alzahrani@uon.edu.au
}

This paper employs data from the Program for International Student Assessment (PISA) 2012 study on mathematics performance in Australian secondary schools to determine the effect of mathematics anxiety on mathematics performance among secondary students. Data of school and student specific factors that are relevant to the Australian educational context are extracted from the PISA 2012 study. These data are used to measure the influence of these factors, as well as mathematics anxiety, on students' mathematics performance. Potential predictive factors are also used in the assessment including gender, socio-economic status (SES) and mathematics anxiety. Findings support the existence of an inverse relationship between mathematics performance and mathematics anxiety whereby the influence of mathematics anxiety varies based on students' gender and SES.

\section{INTRODUCTION}

Mathematics anxiety has been recognised internationally as a debilitating condition among secondary school students (Karimi \& Venkatesan, 2009). Symptoms of mathematics anxiety include tension and nervousness, symptoms which have shown to negatively impact on student ability to answer mathematics questions and deal with numbers (Schillinger, Vogel, Diedrich, \& Grabner, 2018). The severity of mathematics anxiety along with factors causing it are varied across secondary schools with respect to different educational contexts and the susceptibility of students to have or suffer from mathematics anxiety in various degrees depends on various factors. These factors can be social or relevant to the personality of students and can include gender, academic skills, cognitive functioning, the capacity to comprehend and apply new concepts, and the mental capacity to process numbers and discern patterns (OECD, 2014; Ashcraft \& Moore, 2009; Schillinger et al., 2018; Ashcraft, 2002). However, there are some potential predictive factors of both mathematics anxiety and poor mathematics performance which include low socioeconomic status (SES), low self-esteem, poor cognitive functioning, being female, lack of motivation, and negative attitude towards mathematics.

The comprehension along with understanding and retention of mathematics concepts are considered significant in mathematics learning. This requires adequate cognitive functioning among students regardless of pre-existing difficulties in learning mathematics and anxieties that may cause unsatisfactory mathematics performance. In fact, proper cognitive functioning is considered a prerequisite to improve performance in mathematics. Nervousness can interfere with proper cognitive functioning by impeding memory and ability for cognitive reflection, which impedes the ability of students to solve relevant number problems (University of Cambridge, 2019; Luttenberger, Wimmer, \& Paechter, 2018). It is the presence of anxiety towards mathematics as an indicator of cognitive processing deficits among students which is also considered a potential predictor of poor mathematics performance of students.

Teaching skills and approaches are also considered to influence perceptions and the tendency of students to learn mathematics. The perceptions of students can be adversely affected, for example, by using instructional teaching methods such as traditional literacy strategies instead of more motivating and engaging contemporary strategies. This can be due to instructors failing to adopt instructional approaches that link mathematics concepts with daily life aspects in a way that does not undermine the motivation of students to learn mathematics (Luttenberger et al., 2018).

Gender is another factor that can impact the level of mathematics anxiety. Females have been found to be more susceptible to anxiety towards mathematics compared to males (Luttenberger et al., 2018). There is also a tendency of instructors to use mathematics teaching and testing approaches that are more preferable and attractive for one gender which can be the cause of misconceptions in terms of learning mathematics 
for the other gender (Luttenberger et al, 2018). As a result, mathematics instructors are encouraged to use teaching strategies that are suitable and compatible with needs of both genders in order to motivate students to better engage and hence learn mathematics.

It has been found that the effect of mathematics anxiety may last the entire academic life of students when mathematics anxiety is not dealt with effectively (Schillinger et al., 2018). Students with high levels of mathematics anxiety, for example, tend to avoid more mathematics in the post-secondary school stage which is supported by the lack of mathematics focused courses in science, technology and mathematics in college (OECD, 2014; Thomson, Bortoli, \& Buckley, 2013). It is therefore important to try to reduce mathematics anxiety through adopting measures that involve motivating teachers and educational institutions to use suitable instructional strategies that also encourage parents and society involvement to enhance students' confidence and interest in mathematics which also involves demystifying the social stereotype that female aptitude for mathematics is inferior compared to that of males (Luttenberger et al., 2018; Karimi \& Venkatesan, 2009; Justicia-Galiano et al., 2017). This study aims to evaluate the relationship between mathematics anxiety and mathematics performance among students at the secondary school level in Australia.

\section{METHODS}

For the purpose of assessing the effect of mathematics anxiety on mathematics performance among Australian secondary school students, data was collected from 775 secondary schools in the 2012 PISA study. There were 14,481 secondary school students, who were approximately 15 years old (Thomson et al., 2013). To ensure the reliability of national estimates that would be generated for the Australian population, an Australian sample was selected that was larger than the sample of other participating countries' populations in the study; also, the Australian sample included smaller jurisdictions and indigenous zones to expand the study units studied (Thomson et al., 2013). PISA instructors also undertook training on PISA procedures and data collection in the period between July and September 2012 to further improve reliability (Thomson et al., 2013).

The questionnaire of the PISA 2012 study included some core subscales such as mathematics anxiety which covered five anxiety domains: whether secondary school students were feeling helpless, worried about obtaining poor grades, very nervous, very tense, and lastly, were worried about taking a difficult task whenever they were given a mathematics test or were required to solve a mathematics problem. Responses of participants to these items were presented on a four point Likert Scale: from strongly disagree, disagree, agree to strongly agree, which were scored from 1 to 4 respectively with 1 denoting low anxiety and 4 high levels of anxiety. An average anxiety measure was calculated across these subscales and these averages were categorised. The first category represented an average anxiety score of less than 1.75; the second category represented an average anxiety score of between 1.75 and 2.5; the third category represented average anxiety levels between 2.5 and 3.25; and the fourth category represented average anxiety levels between 3.25 and 4. These four categories were denoted as (1), (2), (3) and (4) respectively. Furthermore, four different subscales of each domain: quantity, uncertainty, change and relationship, and shape and space were used to assess the score of mathematics performance. For each subscale, a total between 7 and 10 questions were posed to the study subjects and the sum of correct responses was calculated and used to find the total score out of the possible total score of 35 for each student. To calculate the SES measure, items from the PISA questionnaire were used that consisted of items relating to the number of rooms and cars in a students' house, as well as the presence of computers and Internet connection at home whereby higher values for each of these items, or the presence of the item, reflected a higher measure of SES (OECD, 2014). The measure of SES used for this study was calculated using these items and the specifics of how the SES measure was calculated from these measures is described elsewhere (Alzahrani, Stojanovski, \& Howley, 2017).

Bivariate analyses were performed to examine the relationship between mathematics performance and mathematics anxiety. For this component, mathematics anxiety was used on a categorical scale with four levels. Analysis of variance (ANOVA) was used to compare the average score of mathematics performance across the different levels of mathematics anxiety and the two sample $t$-test was used to 
compare the average mathematics performance between female and male students. Further analysis included SES, gender and mathematics anxiety as predictors of mathematics performance to enable SES and gender to be adjusted for in the model using multilevel models. This analytical approach enabled students to be nested within the schools they belonged to, hence incorporating the evident hierarchies in the data within the modelling technique (Hrițcu, 2015; Mertens, Pugliese, \& Recker, 2016). The school level data enables the probable existence of strong correlations between students in the same school as well as the weaker correlations among students from different schools to be effectively represented within the model.

\section{RESULTS}

Bivariate Analysis of Mathematics Performance against Mathematics Anxiety levels

An inverse relationship between mathematics performance and mathematics anxiety was evident in Figure 1 below which displays side-by-side boxplots comparing mathematics performance across different levels of mathematics anxiety. Mathematics scores decline as mathematics anxiety levels increase.

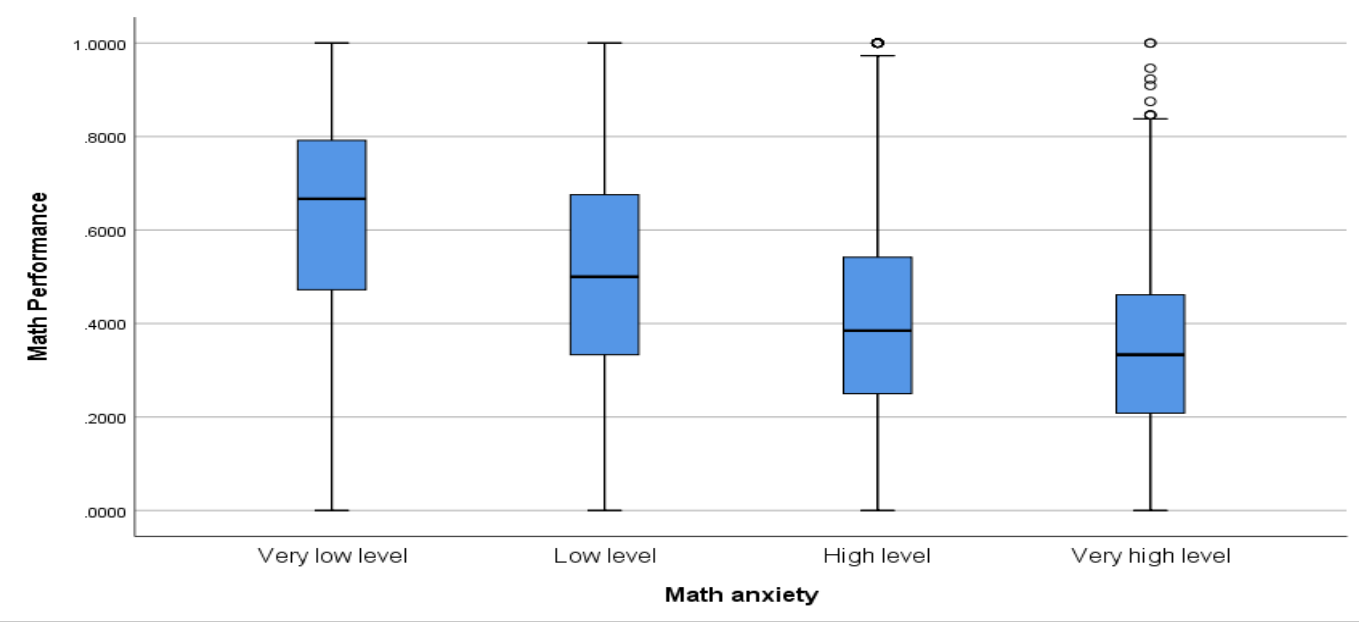

Figure 1: Box-plot for mathematics performance against mathematics anxiety

Mathematics anxiety levels (very low, low, high and very high) significantly differed from each other with respect to average mathematics performance scores with the highest level of mathematics anxiety associated with the lowest average mathematics performance score and vice versa $(p<0.05)$. The multilevel linear regression supports the inverse relationship (math anxiety estimate coefficient $=-0.11, p<0.05$ ), after adjusting for the nested design of the data.

\section{Analysis of Gender effect on mathematics anxiety}

A statistically significant difference in the average anxiety levels between males and female genders was found $(p<0.01)$, with female students significantly more anxious than males. The average anxiety levels of male and female students was 2.30 and 2.54 respectively. The Wilcoxon signed-rank test supported this trend $(\mathrm{df}=1, p<0.01)$.

\section{Analysis of SES on mathematics anxiety}

SES was also found to be a statistically significant predictor of mathematics anxiety $(p<0.01)$. Tukey's post-hoc test confirmed that all three SES groups as statistically different to each other $(p<0.05)$, with the average anxiety scores of 2.63, 2.46 and 2.35 for the low, medium and high SES levels respectively. This inverse trend is depicted graphically in Figure 2. 


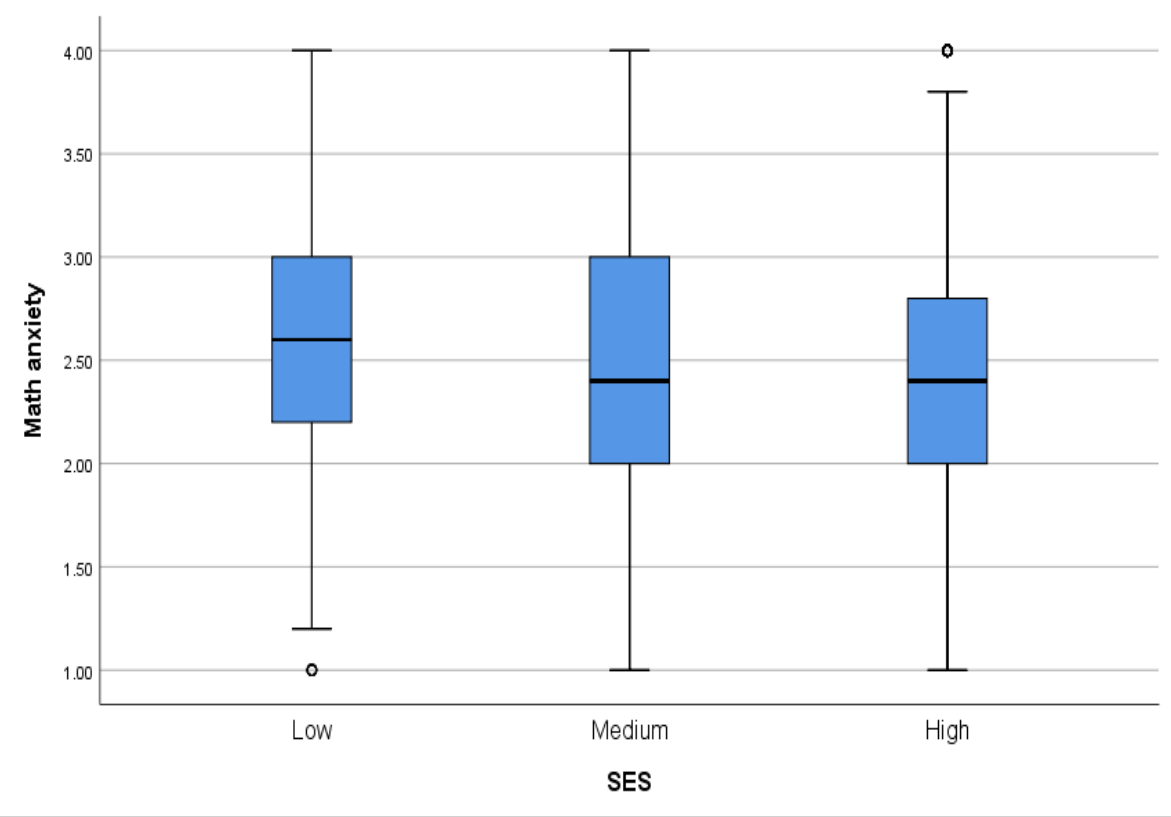

Figure 2: SES and mathematics anxiety box-plotted side-by-side

\section{Gender and mathematics score}

Mathematics performance of males was slightly better than that of females $(t=-6.64, p=0.01)$ (Figure 3). It should be noted though that the mean and median mathematic performances of females are 0.46 and 0.45 respectively, while for males these are 0.49 and 0.47 .

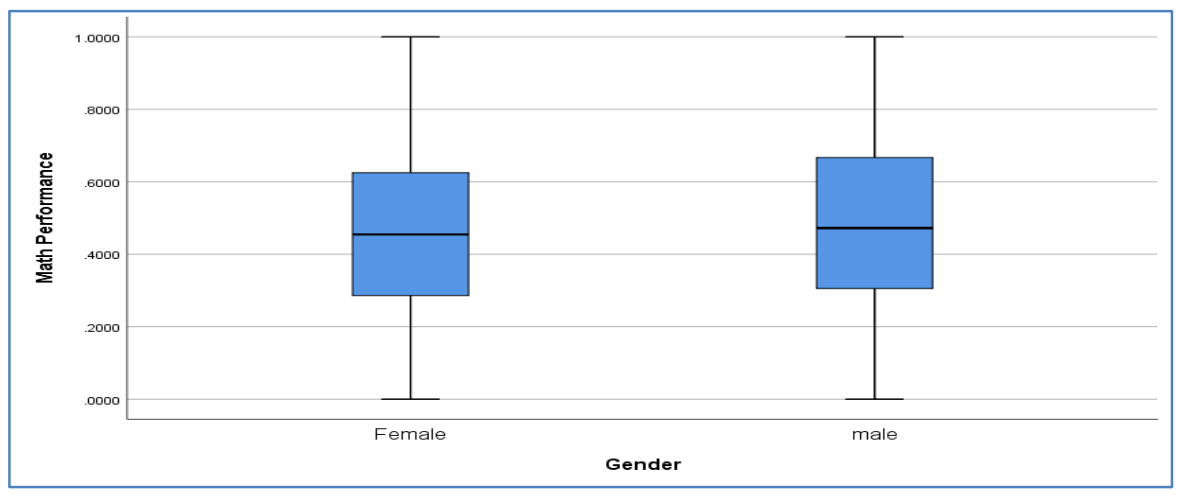

Figure 3: Mathematics performance and gender box-plotted side-by-side

\section{Each Mathematics Subscale by Anxiety}

A side-by-side box plot for performance in the Shape and Space subscale of mathematics shows a negative trend with anxiety levels, as depicted in Figure 4 below. The significant inverse relationship between mathematics performance and mathematics anxiety was consistent for each mathematics subscale (Spearman's rho $(\rho), p<0.01)$ : Shape and Space $(\rho=-0.29)$, Change and Relationship $(\rho=-0.30)$, Quantity $(\rho=-0.29)$, Uncertainty and Data $(\rho=-0.26$. $)$ 


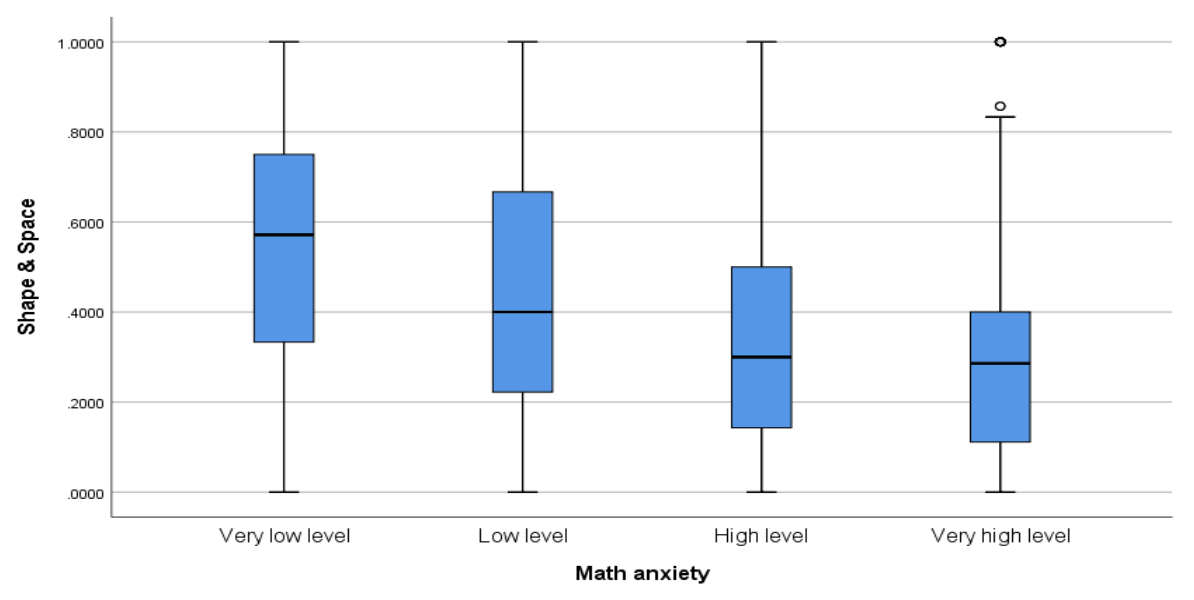

Figure 4: Negative trend when Shape \& Space is box-plotted against mathematics anxiety

\section{CONCLUSION}

Mathematics performance appears to be negatively impacted by mathematics anxiety within Australian secondary schools. Females appear to have higher levels of mathematics anxiety compared to males; and females' mathematics performance appears slightly lower than that of males. Reducing mathematics anxiety could potentially reduce the gender gap in terms of mathematics performance and could encourage more females to study mathematics post-secondary school. Educators are encouraged to modify their instructional strategies and testing methods in mathematics so that they are more compatible with learning needs of both genders in an attempt to reduce anxiety levels of students. This could potentially contribute longer term to more students, and more females, studying mathematics based courses in senior high school and tertiary level to help meet the demand of more suitably qualified employees with quantitative skills in the Australian economic sector and to reduce the gender gap among those in the more mathematically oriented fields.

\section{REFERENCES}

Alzahrani, A., Stojanovski, E., \& Howley, P. (2017). Assessment of Teaching Practices on Mathematics for Students in Qatar. In A. Molnar (Ed.), Teaching Statistics in a Data Rich World, Proceedings of the Satellite conference of the International Association for Statistics Education (IASE).

Ashcraft, M. H., \& Moore, A. M. (2009). Mathematics anxiety and the affective drop in performance. Journal of Psychoeducational Assessment, 27(3), 197-205.

Ashcraft, M. H. (2002). Math anxiety: Personal, educational, and cognitive consequences. Current Directions in Psychological Science, 11(5), 181-185.

Hrițcu, R. O. S. (2015). Multilevel models: Conceptual Framework and Applicability. Acta Universitatis Danubius Economica), 11(5), 72-83.

Justicia-Galiano, M. J., Martín-Puga, M. E., Linares, R., \& Pelegrina, S. (2017). Math anxiety and math performance in children: The mediating roles of working memory and math self-concept. British Journal of Educational Psychology, 87(4), 573-589.

Karimi, A., \& Venkatesan, S. (2009). Mathematics anxiety, mathematics performance and academic hardiness in high school students. International Journal of Educational Sciences, 1(1), 33-37.

Luttenberger, S., Wimmer, S., \& Paechter, M. (2018). Spotlight on math anxiety. Psychology Research and Behavior Management, 11, 311-322.

Mertens, W., Pugliese, A., \& Recker, J. (2016). Nested Data and Multilevel Models: Hierarchical Linear Modeling. In Quantitative Data Analysis, (pp. 61-72). Springer: Cham.

OECD. (2014). PISA 2012 Results in Focus: What 15-year-olds know and what they can do with what they know. https://www.oecd.org/pisa/keyfindings/pisa-2012-results-overview.pdf 
Schillinger, F. L., Vogel, S. E., Diedrich, J., \& Grabner, R. H. (2018). Math anxiety, intelligence, and performance in mathematics: Insights from the German adaptation of the Abbreviated Math Anxiety Scale (AMAS-G). Learning and Individual Differences, 61, 109-119.

Thomson, S., Bortoli, L. D., \& Buckley, S. (2013). PISA 2012 : How Australia measures up: the PISA 2012 assessment of students' mathematical, scientific and reading literacy. Victoria: Australian Council for Educational Research. https://research.acer.edu.au/ozpisa/15

University of Cambridge. (2019). What is Mathematics Anxiety? Retrieved March 22, 2019, from https://www.cne.psychol.cam.ac.uk/math-memory/what-is-mathematics-anxiety 